\title{
A Novel High Gain Voltage-Lift Technique Based Transformer free Non-isolated Quadratic Boost Converter
}

\author{
Pydikalva Padmavathi ${ }^{1}$, Sudhakar Natarajan ${ }^{1 *}$ \\ ${ }^{1}$ School of Electrical Engineering, Vellore Institute of Technology, Vellore, Tamilnadu, India-632014
}

\begin{abstract}
A novel high gain voltage lift technique based transformer free non isolated boost converter is proposed with single switch operating at constant frequency in this paper. This performance of this converter is very good and high efficient compared to the conventional boost converters. The high gain is obtained by applying voltage lift cell to the quadratic boost converter. The simple structure, easy controlling and lower voltage stress. The operating principle with theoretical analysis and simulation results of proposed converter for various loads at $10 \mathrm{kHz}$ frequency are discussed in this paper to compare the performance of this novel boost converter.
\end{abstract}

\section{Introduction}

Nowadays, the application of dc-dc converters is increasing day by day like LED lighting systems, hybrid electrical vehicles, servomotors, computer systems, uninterrupted power supplies, solar photovoltaic systems and green energy systems. The power electronic converters are used in these applications are mainly controlled by switching frequency and pulse width modulation (PWM). In literature there are two different categories of converters isolated and non-isolated [1]-[2]. Isolated converters need high frequency transformer for example push pull, fly back and forward. The usage of high frequency transformer will raise the gain of the voltage, but at the same time conduction losses will be high. The non-isolated converters like boost, buck, buck-boost, SEPIC, CUK, and Zeta converters are not having high frequency transformer leads to low price of the converter, switching losses are low, and high efficiency.

In literature, a great research is carried out on power electronic converters with high voltage gain [3]. To obtain high gain the converters are connected in cascaded, but leads raises the price and efficiency is low. High voltage gain is obtained by using single switch boost converter [4]. Voltage lift technique is applied on the quadratic boost converter which improves high gain with lower switch stress [5]. The source current of the proposed converter is continuous, more suitable for renewable energy applications.

The analysis of the projected converter is explained and differentiated with conventional quadratic boost converter with high gain converters in section 2 . The mathematical modelling of the converter with related waveforms clearly explained in section 3 . The result comparison to estimate and prove the proposed converter is better compared to conventional converter is 
presented in section 4. Finally, the conclusion of the projected converter is added in section 5.

\section{Conventional quadratic high gain boost converter}

Conventional quadratic high voltage gain boost converter is as shown in fig. 1(a). The voltage-lift cell is used in the converter to achieve the gain is higher, there are total two modes of operations that when switch $\mathrm{S}$ is ' $\mathrm{ON}$ ' and 'OFF' positions. When switch $\mathrm{S}$ is turned on the capacitor $\mathrm{C}_{1}$ and inductor $\mathrm{L}_{1}$ are connected in parallel, inductor starts charging by the input voltage source with DT. When switch $\mathrm{S}$ is turned off position the capacitor $\mathrm{C}_{1}$ and inductor $\mathrm{L}_{1}$ both are connected in series and voltage source as input $\mathrm{V}_{\mathrm{i}}$, where stored energy in the inductor and capacitor has been delivered to the load with $\left(\mathrm{V}_{\mathrm{o}}-2 \mathrm{~V}_{\text {in }}\right)(1-\mathrm{D}) \mathrm{T}$.

The related equations to solve the gain of the converter as follows. The ripple current of the inductor iL1 is represented by equation (1)

$\Delta i_{L 1}=\frac{V_{\text {in }} D}{L_{1} f}=\frac{V_{o}-2 V_{\text {in }}}{L_{1} f}(1-D)$

From equation (1) $\mathrm{V}_{\mathrm{o}}$ can be described as follows

$V_{o}=\frac{2-D}{1-D} V_{\text {in }}$

The gain of the converter is $\mathrm{M}={ }_{M}=\frac{V_{o}}{V_{\text {in }}}=\frac{2-D}{1-D}$

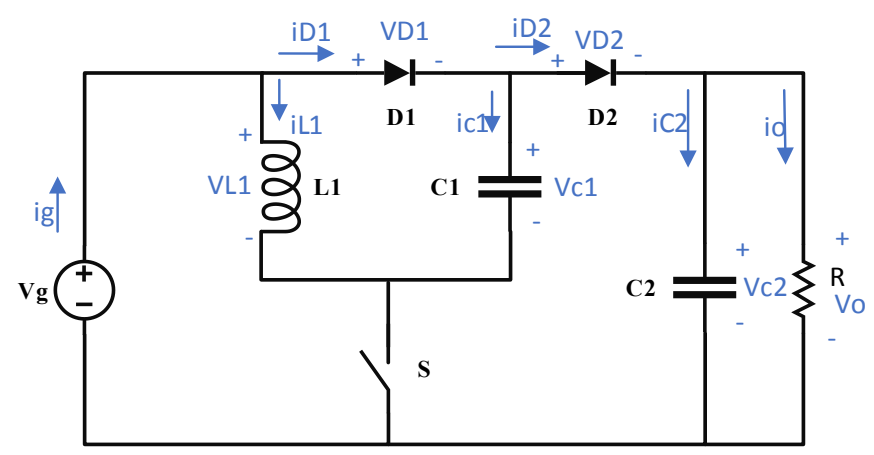

Fig. 1. Conventional quadratic boost converter

\subsection{Modified voltage lift technique quadratic high voltage gain boost converter}

A modified voltage lift technique based quadratic high voltage gain boost converter as shown in fig. 2(a). A novel converter proposed with different modes of operation. The proposed converter consists of single switch, two diodes, three capacitors, and two inductors. To make the analysis of the converter is easier there are few assumptions are as follows.

1. The converter is analysed that when it is in steady state.

2. The capacitors of the proposed converters are large enough, hence capacitor's voltage assumed to be constant.

3. The converter output voltage is to be constant.

4. The switches and diodes of the proposed converter treated as ideal. 


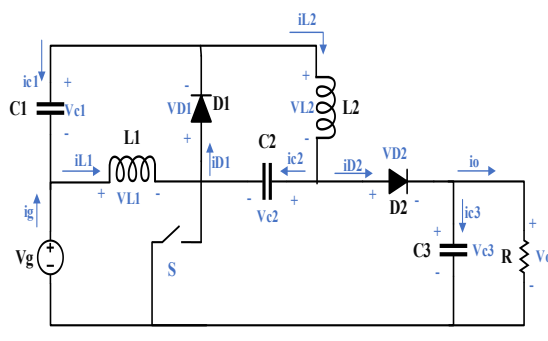

(a)

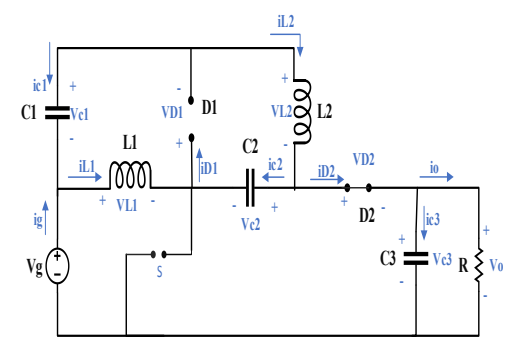

(c)

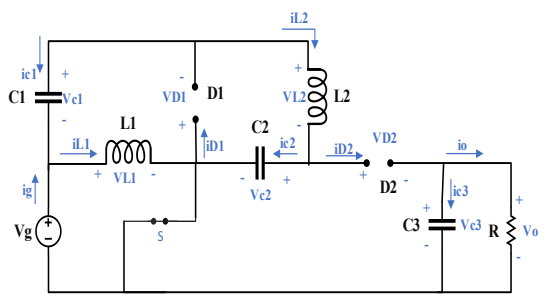

(b)

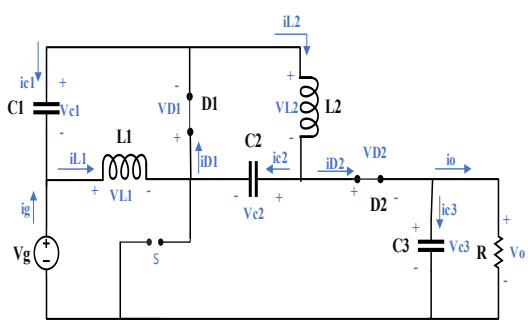

(d)

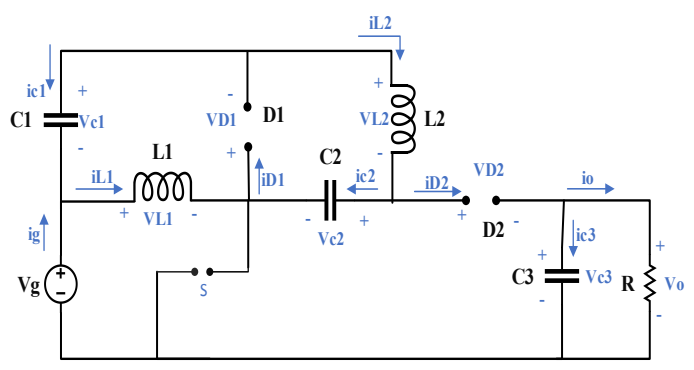

(e)

Fig. 2(a). Modified voltage lift-cell quadratic high gain boost converter; (b) at CCM when S-on (c\&d) at CCM when S-off (e) at DCM

\subsection{Modes of operations of proposed converter}

Mode I: When switch $\mathrm{S}$ is turned $\mathrm{ON}$ the diode $\mathrm{D}_{1}$ and $\mathrm{D}_{2}$ are reverse biased, voltage source vg is directly connected to the inductor $\mathrm{L}_{1}$ and the current increases linearly from minimum to maximum hence, the stored energy is also increased. During this interval of time the source voltage $\mathrm{Vg}$ is connected to the inductor $\mathrm{L}_{2}$ and in series with the capacitors $\mathrm{C}_{1}$ and $\mathrm{C}_{2}$. The current in the inductor $\mathrm{L}_{2}$ also rises linearly to the maximum, Hence the stored energy is also raises and the capacitor $C_{1}$ voltage $V_{C 1}$ is decreased from its higher value and capacitor $\mathrm{C}_{2}$ voltage $\mathrm{V}_{\mathrm{C} 2}$ is increased from its lower value. The equivalent circuit of mode $\mathrm{I}$ is as shown in fig 2(b).

Mode II: When switch $\mathrm{S}$ is turned OFF the diode $\mathrm{D}_{1}$ is reverse biased and $\mathrm{D}_{2}$ goes in forward bias condition, the inductor $\mathrm{L}_{1}$, capacitors $\mathrm{C}_{2}, \mathrm{C}_{3}$ are connected to the load; hence stored energy is starts slowly decreased. The inductor $L_{2}$ and capacitors $C_{1}, C_{3}$ are connected in series hence, the stored energy and inductor current is starts decreasing slowly. The voltage across capacitor $C_{3}$ is increased and $C_{1}$ and $C_{2}$ are decreased. The equivalent circuit is of mode II is as shown in fig $2(\mathrm{c})$. 
Mode III: When switch $\mathrm{S}$ is turned OFF the diodes $\mathrm{D}_{1}$ and $\mathrm{D}_{2}$ are forward biased condition, the current of the capacitor $\mathrm{C}_{2}$ and inductor $\mathrm{L}_{2}$ charges the capacitor $\mathrm{C}_{3}$ and load current. Hence, voltage across the capacitor $\mathrm{C}_{2}$ and $\mathrm{L}_{1}$ are decreased to the lower value and stored energy of capacitor $C_{3}$ is raises to its maximum value. The capacitor $C_{1}$ and inductor $\mathrm{L}_{1}$ are connected in parallel; current through the inductor $\mathrm{L}_{1}$ and stored energy are decreased to lower value. The inductors $L_{1}, L_{2}$, and capacitors $C_{1}, C_{2}$ provides parallel path to the load and current through the inductors is decreased. The equivalent circuit of mode III is as shown in fig 2(d).

Mode IV: when the circuit discontinuous mode of operation when the switch turned off and the diodes $\mathrm{D}_{1}$ and $\mathrm{D}_{2}$ are reverse biased, the inductor current $\mathrm{L}_{1}$ and $\mathrm{L}_{2}$ are goes to zero and stored energy are goes to lower value. The stored energy and voltage across the capacitor $\mathrm{C}_{1}$ and $\mathrm{C}_{2}$ remain constant. Hence, the stored energy and voltage are decreases to its lower value. The equivalent circuit for mode IV is as shown in fig.2 (e). The waveforms of proposed converter are clearly shown in fig.3.

\section{Mathematical analysis of the proposed converter}

By applying KVL for fig 2(b) the voltage across inductor $L_{1} \& L_{2}$ is represented as

$$
\begin{aligned}
& V_{L 1}=V_{g}=L_{1} \frac{d i_{L 1}}{d t} \\
& V_{L 2}=V_{g}+V_{C 1}-V_{C 2}
\end{aligned}
$$

By applying KVL for fig 2(c) \& 2(d) the voltage across the inductor $\mathrm{L}_{1} \& \mathrm{~L}_{2}$ are as follows

$$
\begin{gathered}
V_{L 1}=V_{g}+V_{C 2}-V_{C 3}=-V_{C 1} \\
V_{L 2}=V_{g}+V_{C 1}-V_{C 3}
\end{gathered}
$$

By substituting equation (4) and (6) into voltage balancing rule for inductor $\mathrm{L}_{1}$

$$
V_{g} T_{o n}-V_{C 1} T_{o f f}=0
$$

Where $\mathrm{D}$ is duty cycle of the proposed converter $\mathrm{D}=\mathrm{T}$ on/T

From equation (8) we get

$$
V_{C 1}=\frac{D}{1-D} V_{g}
$$

By considering fig. 2 we observed that

$$
V_{C 1}=V_{C 2}
$$

By substituting equation (5), (7) and (8) into voltage balancing rule for inductor L2 We get the voltage gain of the proposed converter at CCM

$$
\frac{V_{o}}{V_{i}}=\frac{1+D}{1-D}
$$

In discontinuous mode of operation, $\mathrm{D}_{1}, \mathrm{D}_{2}, \mathrm{D}_{3}, \mathrm{D}_{4}$ are the time intervals as shown in Fig.3(b). By applying voltage balancing rule for inductor L1 and L2 following fig 2(e), the gain for proposed converter at DCM can be represented as

$$
\frac{V_{o}}{V_{i}}=\frac{1+D_{1}}{D_{2}+D_{3}}
$$


From (3) and (11), the gain of the proposed converter is higher compared to conventional quadratic boost converter.

The switch or diode utilization factor is as represented

$$
D U F(\text { or }) S U F=\frac{P}{\sum_{K=1}^{n} V_{n} I_{n}}
$$

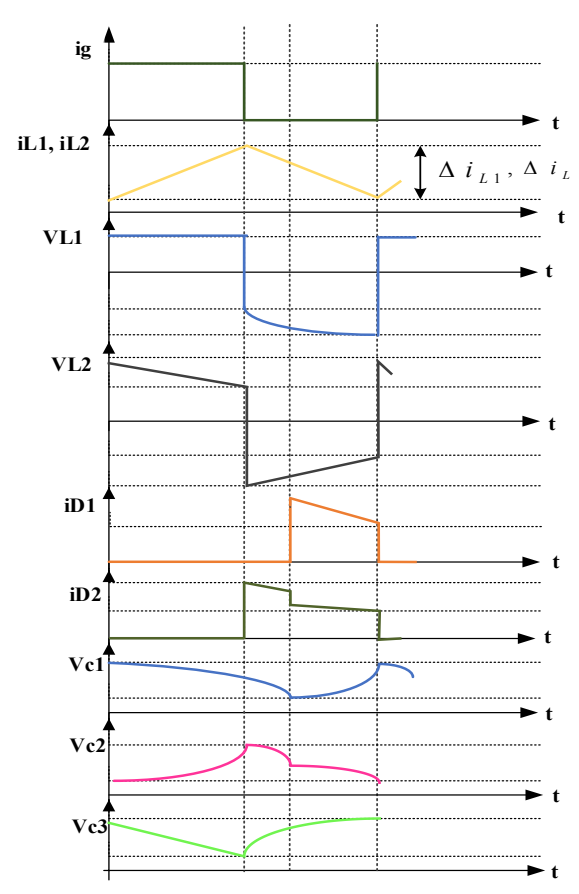

(a)

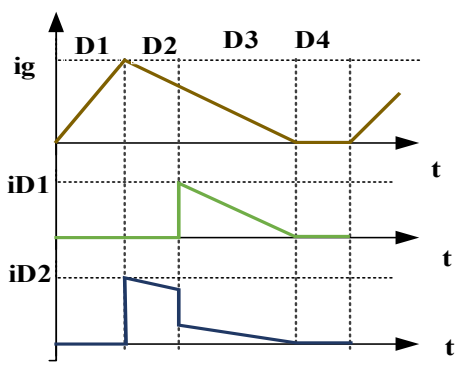

(b)

Fig. 3. Voltage and current waveforms of proposed converter at CCM\&DCM

\section{Result analysis of the converters}

The analysis of the converter is carried based upon the result waveforms of the proposed converter operating at $\mathrm{CCM}$. The modified voltage technique based quadratic boost converter parameters for $120 \mathrm{~W}$ power rating as $\mathrm{V}_{\mathrm{g}}=11 \mathrm{~V}, \mathrm{~V}_{\mathrm{o}}=42 \mathrm{~V}, \mathrm{~L}_{1}=5 \mathrm{mH}, \mathrm{L}_{2}=2 \mathrm{mH}, \mathrm{C}_{1}=\mathrm{C}_{2}=110 \mu \mathrm{F}$, $\mathrm{C} 3=470 \mu \mathrm{F}, \mathrm{R}=13.06 \Omega$, and switching frequency $f_{\mathrm{s}}=10 \mathrm{kHz}$. Fig. 4 shows the waveforms of voltage across the switch $\mathrm{V}_{\mathrm{s}}$ and output voltage $\mathrm{V}_{\mathrm{o}}$. From fig.4 the voltage across the switch is $27 \mathrm{~V}$ and the output voltage $\mathrm{V}_{\mathrm{o}}$ is $42 \mathrm{~V}$. Fig. 4 shows the voltage across the diodes $\mathrm{D}_{1}$ and $D_{2}$ respectively, where the stress across the diodes $D_{1} \& D_{2}$ are $22 \mathrm{~V}$ the simulation results of proposed converter verified with the validation of the theoretical analysis. Fig. 5 clearly shows that the switch stress of proportional converter is better compared to conventional converter. 


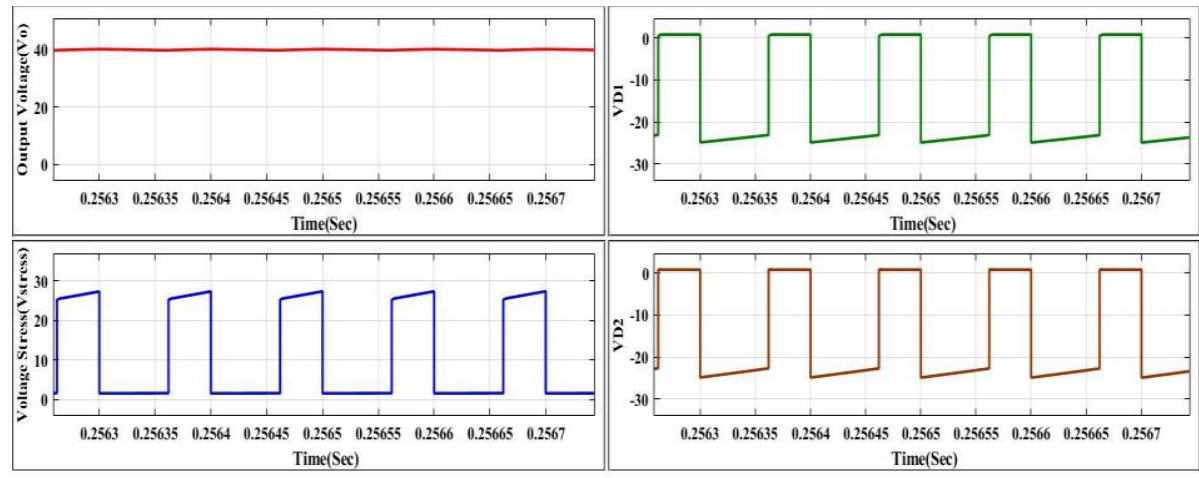

Fig. 4. Waveforms of Output Voltage $\left(V_{o}\right)$, Switch Voltage $\left(V_{s}\right)$, Diode Voltage $V_{D 1} \& V_{D 2}$

Table 1. Comparison $b / w$ converters

\begin{tabular}{|c|c|}
\hline $\begin{array}{c}\text { Type of the } \\
\text { Converter }\end{array}$ & $\begin{array}{c}\text { Gain of the } \\
\text { Converter }\end{array}$ \\
\hline $\begin{array}{c}\text { Quadratic voltage } \\
\text { lift boost } \\
\text { converter[6] }\end{array}$ & $1 /(1-\mathrm{D})^{2}$ \\
\hline $\begin{array}{c}\text { Modified DC-DC } \\
\text { converter with } \\
\text { voltage lift cell [7] }\end{array}$ & $2 /(1-\mathrm{D}) 2$ \\
\hline $\begin{array}{c}\text { Re-lift Boost } \\
\text { converter[5] }\end{array}$ & $(2-\mathrm{D})^{2} /(1-\mathrm{D})^{2}$ \\
\hline Proposed converter & $1+\mathrm{D} /(1-\mathrm{D})$ \\
\hline
\end{tabular}

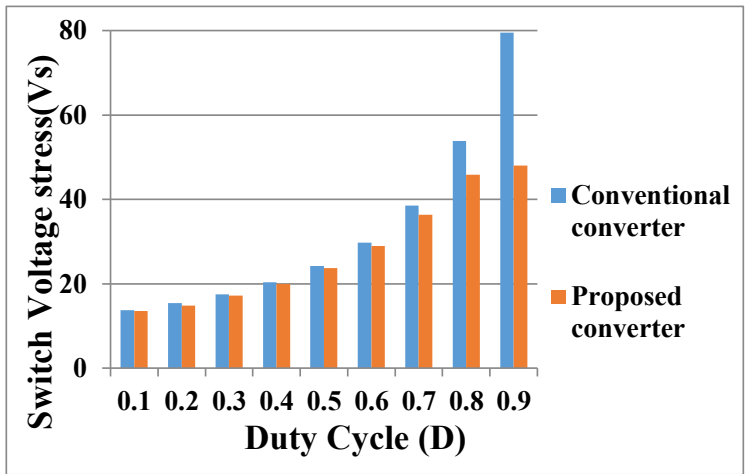

Fig. 5 Switch voltage stress Vs duty-cycle

\section{Conclusion}

The proposed converter with modified voltage technique based quadratic boost converter is clearly analysed. High gain is achieved by using modified voltage cell operated with single switch. From theoretical and simulation analysis it is observed that a great development in the voltage gain of the converter, suitable for different kind of applications that where high voltage gain is required. From Table.1 there are different converters with high gain operating with single switch. But, these converter gains are limited that the converters can boost the voltage when the duty cycle is $\mathrm{D} \leq 0.5$. The proposed converter can operate $\mathrm{D} \leq 0.5$ with high gain and lower voltage stress. By analysing the proposed converter, concluded that can be used with high efficiency for different application.

\section{References}

1. C. Yao, X. Ruan, X. Wang, and C. K. Tse, Isolated buck-boost DC/DC converters suitable for wide input-voltage range, IEEE Trans. Power Electron, 26, 9, (2011). 
2. A. K. Rathore, D. R. Patil, and D. Srinivasan, Non-isolated bidirectional softswitching current-fed LCL resonant DC/DC converter to interface energy storage in DC microgrid, IEEE Trans Ind. Appl., 52, 2, (2016).

3. Y. R. de Novaes, A. Rufer, I. Barbi, A new quadratic, three-level, DC/DC converter suitable for fuel cell application, IEEE Power Conversion Conference, (2007).

4. D. Maksimovic, S. Cuk, Switching converters with wide DC conversion range, IEEE Transactions on Power Electronics, 6, 1, (1991).

5. F. L. Luo, H. Ye, Positive output super-Lift Converters, IEEE Transactions on Power Electronics, 18,1, (2003).

6. J. A. Morales-Saldana, R. Galarza-Quirino, J. Leyva-Ramos, Multiloop controller design for a quadratic boost converter, IET Power Applications., 1, 3, (2007).

7. S.Zhang, J.Xu, P.Yang, Single switch high gain quadratic boost converter based on voltage-lift-technique, IEEE International Power \& Energy Conference (IPEC), (2012). 